\title{
PROJETO SÁBADO NO CAMPUS ESPORTES ADAPTADOS: DANDO VISIBILIDADE AO SERVIÇO EXTENSIONISTA NA UFSC
}

\author{
Luciano Lázzaris Fernandes ${ }^{1}$ \\ João Bosco da Mota Alves ${ }^{2}$ \\ Roger Lima Scherer ${ }^{3}$
}

\section{Resumo}

No cenário acadêmico, encontrar cursos que disponibilizam discussões sobre temas voltados às pessoas com deficiência ainda não é uma realidade para muitas Instituições de Ensino Superior. Gerenciar propostas e ações para este segmento não nos parece tão fácil. Várias são as dificuldades: de relacionamentos individuais e coletivos; de estrutura organizacional das instituições; e de gestar, criar e disseminar novos conhecimentos para se trabalhar com esta população. Oferecer serviços acadêmicos de extensão a essa população permite identificar, preparar, atuar e disseminar constantemente novos conhecimentos; conhecimentos estes fundamentais para propor aos usuários deste serviço melhorias na qualidade de vida, bem como contribuir, também, na formação dos futuros profissionais para atender esta demanda da população. Este estudo busca abordar a importância dos serviços acadêmicos de extensão para esta população. Primeiro, serão apresentados conceitos sobre prestação de serviços, extensão universitária, pessoas com deficiência, e, num segundo momento, abordaremos a importância dos serviços prestados pela universidade para grupos especiais e a sua relação com a aquisição do conhecimento.

Palavras-chave: Extensão universitária. Serviços. Aquisição do conhecimento. Pessoa com deficiência.

\section{PROJECT SATURDAY IN THE ADAPTED CAMPUS SPORTS: GIVING VISIBILITY TO THE SERVICE EXTENSION IN UFSC}

\begin{abstract}
In the academic scene, to find courses that offer discussions on subjects directed to the people with disability is not yet a reality for many Institutions of Superior Education. To manage proposals and action for this segment does not seem so easy. Several are the individual and collective difficulties of relationships, organizational structure of the institutions and, to

\footnotetext{
${ }^{1}$ Possui graduação em Administração de Empresas pela Universidade do Vale do Itajaí (1982), graduação em Educação Física pela Fundação Universidade Regional de Blumenau (1984), mestrado em Educação Física pela Universidade Gama Filho (1992) e doutorado em Engenharia e Gestão do Conhecimento pela Universidade Federal de Santa Catarina (2009). Atualmente é professor adjunto da Universidade Federal de Santa Catarina. Tem experiência na área de Educação Física, com ênfase em Educação Física, atuando principalmente nos seguintes temas: atividade motora adaptada, pessoa portadora de deficiência, integração inclusão, esportes adaptados e educação física especial.e-mail: luciano@cds.ufsc.br

${ }^{2}$ E-mail: jbosco@inf.ufsc.br

${ }^{3}$ E-mail: rogerlscherer@gmail.com
} 
manage, create and spread new knowledge to work with this population. To offer extension's academic services to this population allows constantly identifying, preparing, acting and spreading this new knowledge, which is the basic one to consider to the users of these service improvements in the life quality as well as contributing in the formation of the professional futures to take care of this population's demand. This study looks to approach the importance of the academic extension's services for this population, in this direction we will present concepts on rendering of services, university extension, people with disability, and later, we will approach the importance of the services given by the university for special's groups and its relation with the knowledge acquisition.

Keywords: University extension. Services. Knowledge acquisition. Person with disability.

\section{INTRODUÇÃO}

Temos acompanhado, nas últimas décadas, a implementação de políticas públicas de inclusão social nos vários setores da sociedade. Vários são os eventos internacionais, tais como: o de Salamanca em 1994 e o de Guatemala em 2001, que vêm procurando despertar a conscientização dos governantes, pesquisadores, educadores, entre outros, a criarem e disseminarem conhecimentos, que viabilizem a redução dos preconceitos e que garantam às pessoas com deficiência seus direitos constitucionais (BRASIL, 2007). Sendo assim, algumas Instituições de Ensino (IES) estão se adaptando a esta nova política de inclusão social, tanto estruturalmente (arquitetura), para poder atendê-los em seus espaços físicos, como na aquisição e disseminação dos conhecimentos com vistas à formação profissional dos acadêmicos. Estas ações acadêmicas tentam garantir que o processo inclusivo seja feito com qualidade.

Um dos caminhos utilizados por algumas instituições de ensino superior para oportunizar esta preparação profissional e oferecer um serviço de qualidade a sua comunidade é através da extensão universitária. No I Encontro de Pró-Reitores de Extensão das Universidades Públicas Brasileiras, realizado no Distrito Federal em 1987, a extensão foi considerada como:

\footnotetext{
Processo educativo, cultural e científico que articula o ensino e a pesquisa de forma indissociável e viabiliza a relação transformadora entre a universidade e a sociedade. A Extensão é uma via de mão-dupla, com trânsito assegurado à comunidade acadêmica, que encontrará, na sociedade, a oportunidade da elaboração da práxis de um conhecimento acadêmico. (NOGUEIRA, 2000, p.11).
} 
$\mathrm{Na}$ área da Educação Física, esta discussão não é diferente. Estudos da inclusão de uma disciplina que tratasse dessas questões vêm, desde o início da década de 80 do século passado. Por ser uma nova área de conhecimento, muito ainda se tem a propor, criar e disseminar esses novos procedimentos metodológicos, com objetivos de melhor atendê-los em todos os níveis educacionais e em seus clubes ou organizações desportivas.

Nesta linha, podemos perceber que os serviços acadêmicos de extensão desenvolvidos em universidades podem ser a gênese de novos conhecimentos, onde, conforme em Nonaka \& Takeuchi (1997), o conhecimento possa ser socializado, externalizado, combinado e internalizado, em um ambiente acadêmico favorável, tornando-se contínuo e dinâmico, formando uma verdadeira comunidade de prática.

Todo o serviço acadêmico de extensão universitária necessita de constante intervenção de uma equipe, que troque informações e conhecimentos, os quais são fundamentais para a execução de um projeto de extensão, pois cada atividade desenvolvida é única e os envolvimentos dos participantes ocorrem simultaneamente. Uma prestação de serviço maldesenvolvida pode colocar em risco todo desenvolvimento do projeto.

Há uma necessidade de se definir o que seja serviço e, por sua vez, serviços acadêmicos para termos clareza do que estamos realizando dentro de uma IES. Segundo Hoffman (2001), podemos encontrar serviços em todos os lugares. Esses serviços incluem negócios que podem visar a lucros ou não, podem ser oferecidos por entidades ou organizações públicas ou privadas, e podem ser executados por pessoas com grandes qualificações ou sem nenhuma qualificação profissional. Em uma IES, podemos encontrar três tipos de serviços: Ensino, Pesquisa e Extensão.

Nas Instituições Federais de Ensino Superior (IFES) encontramos algumas discussões quando falamos em serviços. Este artigo tem a intenção de clarear o que sejam serviços acadêmicos de extensão e sua relação com a aquisição do conhecimento em um projeto de extensão voltado às pessoas com deficiência: o projeto "Sábado no Campus: Esportes Adaptados", realizado no Departamento de Educação Física do Centro de Desportos da Universidade Federal de Santa Catarina.

Este estudo busca abordar a importância dos serviços acadêmicos de extensão para esta população. Neste sentido, apresentaremos conceitos sobre prestação de serviços, extensão universitária, pessoas com deficiência, e, num segundo momento, abordaremos a importância dos serviços prestados pela universidade para grupos especiais e a sua relação com a aquisição do conhecimento. 


\title{
Extensão Universitária
}

No Fórum Nacional de Pró-Reitores de Extensão das Universidades Públicas Brasileiras (1990, p.26) ficou firmado que:

\begin{abstract}
A extensão é um dos espaços estratégicos para a promoção de atividades acadêmicas, de caráter interdisciplinar, integrando grupos e áreas distintas do conhecimento, contribuindo à modificação progressiva da forma de fazer ciência e da transmissão desse tipo de saber e revertendo a tendência historicamente dominante de compartimentação do conhecimento da realidade.
\end{abstract}

A extensão, entendida como prática acadêmica que interliga a universidade nas suas atividades de ensino e pesquisa com as demandas da maioria da população, possibilita essa formação do profissional cidadão e se credencia, cada vez mais, junto à sociedade como espaço privilegiado de produção do conhecimento significativo para a superação das desigualdades sociais existentes.

Para Nogueira (2005, p. 11),

\begin{abstract}
A extensão é, então, resgatada como um meio através do qual a universidade vai cumprir sua função social. Repensar a extensão enquanto atividade acadêmica significava colocá-la ao lado do ensino e da pesquisa, na cadeia de produção e difusão do conhecimento. Significava entendê-la como o instrumento que vai possibilitar a democratização do conhecimento produzido e ensinado na universidade e atender às demandas mais urgentes da população. Ao mesmo tempo, ela se constitui em uma forma privilegiada, por meio da qual a universidade avalia e submete à avaliação da sociedade o conhecimento que produz, pelo confronto com situações concretas.
\end{abstract}

Há um entendimento que os projetos de extensão oportunizam desenvolver aspectos didáticos e treinamentos em torno das adaptações e das técnicas de manejo de populações especiais, proporcionando a comunidade acadêmica oportunidades de experimentar situações reais de atendimento à clientela beneficiada.

Outro aspecto importante é a possibilidade da criação de laboratórios onde os estudos científicos possam estar atrelados à formação acadêmica, dinamizando o intercâmbio de pesquisa entre outros profissionais, ou seja, o compartilhamento das ideias.

\section{Pessoa com Deficiência}


Muito se tem discutido sobre as terminologias mais corretas e menos estigmatizantes quando se trata de pessoas que necessitam de atenção especial. O termo "deficiência" muitas vezes era atribuído à negação de "eficiência", do "incomum para o comum", da "incapacidade para a capacidade". Autores como Ribas (1987), Goffman (1982), Bianchetti \& Freire (1998), Fonseca (1995) manifestaram-se a respeito destas questões, direcionando o eixo das discussões por caminhos que tentavam mostrar os equívocos e as contradições geradas por elas.

$\mathrm{Na}$ literatura especializada, encontramos várias definições de termos a serem utilizados para caracterizar esta população, deixando, muitas vezes, os leitores confusos, pois ora são chamados de pessoas com necessidades especiais, ora como pessoas portadoras de necessidades especiais, ora como pessoas portadoras de deficiência, entre outras definições.

Segundo Sassaki (2003), as discussões mundiais envolvendo as pessoas com deficiência, aí se encontrando também o Brasil, chegaram a uma determinação segundo até essas próprias pessoas que, mundialmente, gostariam de serem chamadas de "pessoas com deficiência". Segundo a "Convenção Internacional Sobre os Direitos das Pessoas com Deficiência", aprovada pela ONU em 25 de agosto de 2006, atribui-se o uso desta expressão a pessoas que apresentam perda ou anormalidade de uma estrutura ou função psicológica, fisiológica ou anatômica, gerando incapacidade para o desempenho de atividade, dentro do padrão considerado normal para o ser humano. (ONU, 2007).

\section{Serviços}

Segundo Kotler (2000, p. 448), “Serviço é qualquer ato ou desempenho, essencialmente intangível, que uma parte pode oferecer a outra e que não resulta na propriedade de nada. A execução de um serviço pode estar ou não ligada a um produto concreto". Já em Gianesi e Correa (1994, p. 57) consta que "Os serviços buscam atender às expectativas dos consumidores em relação a determinado conjunto de necessidades." Para Grönroos (2006, p. 90), “O serviço é basicamente algo imaterial e pode ser caracterizado como uma atividade em que a produção e o consumo se dão simultaneamente, em grande medida".

Hoffman (2001) associa serviço com ato, esforços ou desempenho. Esta forma de ver os serviços está relacionada com o que entendemos por serviços acadêmicos de extensão na área da atividade física. Muitas das atividades oferecidas nesta área de conhecimento são 
realizadas de acordo com o que este autor apresenta. Os envolvidos têm um grande desprendimento físico, as atividades são envolventes e, por sua vez, necessitam de um grande desempenho para a sua execução.

Para Gianesi e Correa (1994), as atividades de serviços apresentam como características básicas:

- a intangibilidade, ou seja, o serviço não pode ser manuseado nem possuído pelo cliente. O cliente vive a ação do serviço;

- a necessidade da presença do cliente, o serviço inicia-se com a solicitação e envolvimento do cliente;

- os serviços serem produzidos e consumidos simultaneamente.

Em um pacote de serviço devem estar previstos, segundo Fitzsimmons, Fitzsimmons e Horbe (2000):

- Instalações de apoio: são as instalações e os equipamentos utilizados no serviço. As IES muitas vezes disponibilizam os materiais a serem utilizados, mas, quando se trabalha com pessoas com deficiência, em alguns casos esses são adaptados ou confeccionados pelos próprios integrantes do grupo.

- Bens facilitadores: são os bens consumidos ou utilizados no serviço.

- Serviços explícitos: são os benefícios claramente percebidos pelo cliente como resultado da prestação do serviço.

- Serviços implícitos: são os benefícios psicológicos que o cliente pode obter com a prestação do serviço.

\section{Serviço de extensão universitária para pessoas com deficiência}

$\mathrm{Na}$ área da educação física, o período compreendido de 1981 a 1987 foi fundamental para a inclusão de disciplinas nos cursos de Educação Física que possibilitassem aos futuros profissionais um embasamento teórico para trabalhar com populações especiais, entre elas as pessoas com deficiência.

Em 1987, o Parecer n²15/87 do MEC (BRASIL, 1987) propunha como sugestão a inclusão de disciplinas no currículo do Curso de Educação Física que tratassem de atividades físicas para pessoas com deficiência. Em 16 de junho do mesmo ano, a Resolução no 03 do Conselho Federal de Educação determinou um prazo de dois anos para a implantação do novo Currículo dos Cursos de Educação Física, e, com esta, a possibilidade de inclusão desta disciplina. (UNIVERSIDADE FEDERAL DE SANTA CATARINA, 2010). 
Quando se discute formação acadêmica, vem em mente o que as IES estão oferecendo para a qualificação dos seus futuros profissionais. A base desta qualificação está principalmente no envolvimento acadêmico, além das atividades de ensino, nas atividades de pesquisa e extensão. Entende-se ser à base de sustentação desta formação profissional a indissociabilidade entre ensino, pesquisa e extensão.

Este artigo vem tratar apenas de um dos alicerces da instituição: a extensão universitária; serviço acadêmico que requer compromisso pessoal e coletivo.

Trabalhar com projetos de extensão junto a estas populações permite uma aproximação da universidade com esta comunidade.

Entendendo a extensão universitária como uma prestação de serviço oferecido pela IES para as pessoas com deficiências (cliente), buscamos em Gianesi e Correa (1994) as características desses serviços para termos uma melhor compreensão e responsabilidade na execução das atividades a serem desenvolvidas. Os autores citam que os serviços são intangíveis, há a necessidade da presença do cliente, e são produzidos e consumidos simultaneamente.

Quando os autores falam da intangibilidade do serviço, fica clara esta percepção nas atividades corporais desenvolvidas em alguns projetos de extensão na área da educação física, pois o cliente está ativamente envolvido nas atividades propostas. Em Parasuraman, Zeithaml e Berry (2006) os serviços também não são considerados objetos, são oferecidos. Neste sentido, podemos perceber um envolvimento e comprometimento dos que os executam. Logo, nestas atividades, há uma interação concreta entre quem os executa e quem os recebe.

Podemos perceber o quanto as atividades corporais desenvolvidas nas aulas têm uma aproximação com esta intangibilidade quando Lãs Casas (2006, p. 18) afirma que "serviço é a parte que deve ser vivenciada, é uma experiência vivida, é desempenho".

Os serviços de extensão não ocorrem sem a presença dos usuários (clientes), esta é outra característica dos serviços.

Com a inclusão de disciplinas na graduação do curso de Educação Física que abordam sobre as pessoas com deficiência, houve uma necessidade de as IES buscarem parcerias com as associações e instituições que desenvolvem trabalhos com esta população para haver uma aproximação entre ambos. De um lado, está quem oferece o serviço e precisa da presença dessas pessoas para oportunizar aos acadêmicos esta vivência e, por sua vez, produzir e disseminar os conhecimentos obtidos nestas atividades, e, de outro lado, está quem necessita 
deste serviço para melhorar sua qualidade de vida e ter a possibilidade de demonstrar suas habilidades e potencialidades.

Muitas vezes, esses serviços acadêmicos são solicitados por esta população, mas, infelizmente, pela falta de interesse, comprometimento ou mesmo conhecimento de alguns docentes, esta solicitação não é atendida.

Uma IES comprometida com a qualidade de vida de sua comunidade e com a formação dos seus acadêmicos deve ir ao encontro dessas associações e instituições, pois esta é uma ação da Universidade, conforme comentam Souza (2000) e Nogueira (2005).

Nos projetos de extensão, as atividades a serem oferecidas são planejadas e discutidas em pequenos grupos. Nesse momento, essas atividades são apenas intenções ou propostas. $\mathrm{O}$ serviço só acontece realmente quando os executores as colocarem em prática, ou seja, com a presença e a participação dos clientes (usuários destes serviços).

A extensão universitária é uma prestação de serviço da universidade para com a comunidade, na qual de um lado está quem vai propor e/ou executar o serviço e do outro quem vai recebê-lo, consumi-lo (cliente). Observa-se, em determinadas situações, que a mesma pessoa que está executando o serviço (acadêmico) a um cliente (comunidade) pode também ser um cliente do sistema educacional, pois, antes de desenvolver sua atividade, ele também está em processo de formação e, portanto, recebendo serviços (ensino), em que de um lado está o professor (o executor do serviço) e, de outro, o aluno (cliente).

$\mathrm{Na}$ Universidade Federal de Santa Catarina (UFSC), por exemplo, segundo a Resolução Normativa n. ${ }^{\circ}$ 03/CUN/09, de 08 de dezembro de 2009, quem presta o serviço de extensão é a instituição, através de programas ou projetos, muitas vezes propostos por professores ou servidores técnico-administrativos.

O quadro abaixo representa o modelo da UFSC de quem executa o serviço e quem é o cliente deste serviço.

\begin{tabular}{|c|c|c|c|}
\hline $\begin{array}{l}\text { Prestador } \\
\text { do } \\
\text { serviço }\end{array}$ & $\begin{array}{l}\text { Atividades } \\
\text { acadêmicas }\end{array}$ & $\begin{array}{c}\text { Executor } \\
\text { do } \\
\text { serviço }\end{array}$ & Cliente \\
\hline \multirow{3}{*}{ UFSC } & ENSINO & Professor & Acadêrnico \\
\hline & PESQUISA & \multirow{2}{*}{$\begin{array}{l}\text { Professor } \\
\text { STA } \\
\text { Acadêmico }\end{array}$} & \multirow{2}{*}{$\begin{array}{l}\text { Comunidade } \\
\text { (pessoas ou } \\
\text { organizaçốes) }\end{array}$} \\
\hline & EXTENSÃO & & \\
\hline
\end{tabular}

Tomando como exemplo o caso da UFSC e, segundo o "Sistema de Operação de Serviço" de Gianesi e Correa (1994), podemos observar, dentro da comunidade universitária, 
vários executores dos serviços acadêmicos. Quanto ao professor, ele poderá estar na linha de frente (Front Office) em todas as atividades oferecidas ou na retaguarda (Back Room) conforme sua atuação. Ao servidor técnico-administrativo poderá também ocupar a mesma situação, mas, por determinação legal, somente nas atividades de pesquisa e extensão, pois o ensino está ao encargo do docente. Isso não significa que o servidor técnico-administrativo não possa participar deste processo de ensinar, tendo em vista que alguns têm formação específica na área pedagógica. Aos acadêmicos, preferencialmente estarão na linha de frente na execução dos serviços de extensão e pesquisa.

\section{Serviço acadêmico de extensão e a aquisição do conhecimento}

Como já foi discutido, o projeto de extensão serve para que os docentes oportunizem seus alunos a vivenciarem e a se depararem com as realidades que irão enfrentar em seus ambientes de trabalhos, bem como para desenvolver neles os conhecimentos, já citados por Nonaka e Takeuchi (1997) de tácitos e explícitos.

Os novos acadêmicos, quando ingressam na universidade, deparam-se com uma gama de opções de futuras intervenções profissionais dentro de seus cursos, que podem deixá-los, à princípio, em dúvidas por onde começar a se envolver nos projetos oferecidos.

No curso de Educação Física não é diferente. Muitas vezes, ao se engajarem nos projetos de extensão, percebem que são desprovidos de conhecimentos para lidar com determinadas atividades ou mesmo se relacionarem com determinados grupos de pessoas.

A possibilidade de se envolverem nas atividades acadêmicas oferecidas pela instituição poderá ajudá-los a escolher pelos quais pretendem conduzir sua profissão. Esta definição, às vezes, poderá estar relacionada com sua história de vida ou mesmo por interesses pessoais.

Ao ingressar na vida acadêmica, os alunos dispostos a desenvolver seus estudos com pessoas com deficiência muitas vezes vêm sem nenhuma experiência ou, simplesmente, sem observação nesta área (Educação Física Adaptada), pois como as oportunidades dessas pessoas participarem de atividades corporais são reduzidas, podem levar, pela falta de informação, ao desconhecimento de suas reais habilidades e potencialidades. As predisposições em desenvolver seus estudos podem estar atreladas a interesses pessoais ou por entenderem que serão também co-responsáveis no processo inclusivo dessas pessoas na sociedade. 
Nesse sentido, os serviços prestados a esta população através da extensão universitária poderão oportunizar a aquisição de novos conhecimentos. Ao estar participando destes serviços, estará se engajando em uma comunidade acadêmica (grupo de estudos). Nesta comunidade, o fluxo de informações e as discussões permitirão, além de adquirir os conhecimentos através das práticas/experiências corporais (conhecimento tácito) adquirir, também, conhecimentos através de documentos, livros, textos elaborados e estruturados pelo grupo ou pela comunidade científica (conhecimento explícito).

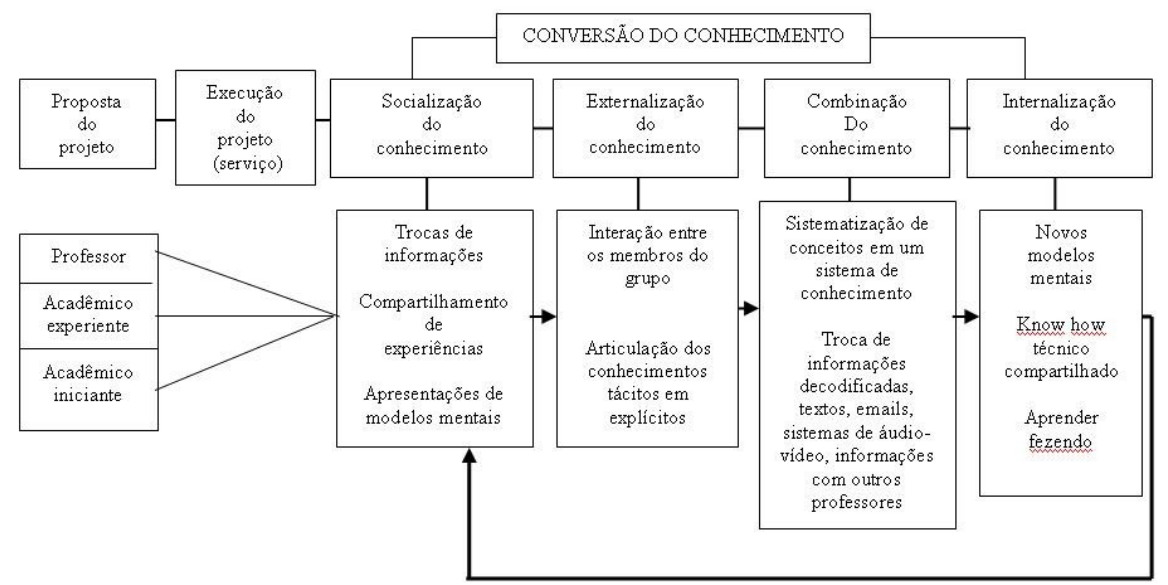

A participação nesta comunidade permitirá ao acadêmico se envolver diretamente no que chamamos de espiral do conhecimento de Nonaka e Takeuchi (1997). Nestes ambientes, os conhecimentos são constantemente modificados. A cada preparação e execução das atividades (serviços), surgem novos dados e informações que serão apresentados, discutidos e reelaborados através de um fluxo informacional estruturado pela comunidade acadêmica.

Essa comunidade está constituída basicamente por professores e acadêmicos, e, em alguns, casos encontram-se servidores técnico-administrativos. A diversidade de conhecimentos individuais nesta comunidade a torna um ambiente facilitador da gênese do conhecimento.

Quando falamos da importância da participação dos acadêmicos nos serviços de extensão e, por sua vez nas discussões de grupos, é pelo alto valor da transferência de conhecimentos que esta atividade acadêmica produz. As trocas de informações entre os participantes, principalmente aos iniciantes, garantem a continuidade do projeto e o que se considera mais significativa: a aquisição de novos conhecimentos.

No ambiente da extensão universitária, pode-se perceber uma relação muito próxima com o quadro de conversão do conhecimento de Nonaka e Takeuchi (1997). 
Neste quadro, nota-se que a proposta de execução dos serviços de extensão está, num primeiro momento, sendo planejada pela equipe. Neste planejamento, as atividades a serem desenvolvidas serão distribuídas de acordo com a capacidade e habilidade em aplicar os conhecimentos (tácitos e explícitos) aos clientes. Após a efetivação dos serviços, inicia-se o processo de conversão dos conhecimentos tácitos em explícitos até a nova aplicação das novas atividades.

O fluxo de informações ocorridas nestes projetos de extensão varia com a capacidade e a habilidade do grupo em usar os veículos necessários para a sua disseminação. O uso das Tecnologias de Informação e Comunicação (TICs) pode servir para a disseminação das informações. As comunidades virtuais são exemplos reais dessas disseminações, pois os aspectos tempo (período para proceder e encaminhar as informações) e o espaço (distância que essas informações percorrerão) poderão ser reduzidos.

Projetos de extensão que executam serviços às pessoas com deficiências precisam estar preparados e informados com o que há de melhor e mais atual em termos de tecnologias, metodologias e materiais. A busca e a aquisição de conhecimentos podem garantir uma boa execução dos serviços, garantindo satisfação aos seus clientes, permanência nos projetos, e melhoria na qualidade de vida.

\section{O projeto sábado no campus: esportes adaptados}

Para entender um pouco das atividades paradesportivas desenvolvidas no projeto Sábado no Campus, faz-se necessário compreender um pouco da história dessas atividades.

A relação pessoa com deficiência e atividade esportiva teve um grande marco durante as Grandes Guerras Mundiais. Neste período, o objetivo principal era reabilitar os soldados e civis mutilados nos campos de batalha. Médicos neurologistas utilizaram-se dos gestos mecânicos de alguns esportes da época para auxiliar no tratamento e recuperação dessas vítimas.

O esporte, como prática para pessoas com deficiência física, efetivou-se na Inglaterra, no ano de 1944, mais precisamente na cidade de Aylesbury, base naval americana, onde foi construído o Hospital de Stock Mandeville. Um neurocirurgião alemão, Sir. Ludwig Guttmann, foi responsável pela direção deste hospital, que introduziu as atividades esportivas como parte essencial no tratamento dos lesionados medulares. Conhecendo a mecânica de movimentos de alguns esportes tradicionais como o arco e flecha, tênis de mesa e o arremesso 
de dardo, o senhor Guttmann introduziu-os como forma terapêutica e de inserção social no tratamento dos vitimados da guerra. Com essa dinâmica no tratamento, deu-se início o que hoje chamamos de esportes adaptados. Pode-se ver claramente a contribuição do conhecimento tácito e explícito para a melhoria da condição física e psíquica dessas pessoas.

No Brasil, as práticas dos esportes adaptadas iniciaram no ano de 1958, após a chegada de dois atletas paraplégicos vindos de tratamentos fisioterápicos nos Estados Unidos.

No cenário internacional, crescia o estudo relacionado às pessoas com deficiência e às atividades físicas adaptadas. No Brasil, com o movimento paradesportivo, surgiu a necessidade do trabalho especializado para este grupo de pessoas, germinando no meio acadêmico esta área de conhecimento, Educação Física Adaptada.

Entende-se que esta área do conhecimento tem como objetivo oferecer atendimentos especializados aos participantes, respeitando as diferenças individuais, visando proporcionar o desenvolvimento global dessas pessoas, tornando possível não só o reconhecimento de suas potencialidades, como também, sua integração na sociedade.

O projeto Sábado no Campus: Esportes Adaptados teve sua origem em 1997, por iniciativa da Reitoria.

O projeto buscou oferecer, nestes quase 13 anos de história, a esta população várias modalidades paradesportivas. Estas têm várias finalidades, sejam no simples fato de estarem envolvidos na atividade física e recreativa, seja na iniciação ou treinamento de alguns esportes competitivos.

A seguir, elencamos algumas modalidades paradesportivas desenvolvidas no projeto:

- Goalball - esporte praticado pelas pessoas cegas ou com baixa visão.

- Atletismo - para pessoas com deficiência física, visual e intelectual.

- Natação - para pessoas com deficiência física, visual, intelectual, e auditiva.

- Xadrez - para pessoas com deficiência física e visual.

- Tênis de Campo em Cadeira de Rodas - pessoas com deficiência física.

- Handebol em Cadeira de Rodas - para pessoas com deficiência física.

- Bocha Adaptada - para pessoas com grandes comprometimentos motores.

- Polibaty - para pessoas com grandes comprometimentos motores - Esporte adaptado do Tênis de Mesa.

- Voleibol sentado (a ser implementado em 2010) - pessoas com deficiência física.

- Rubgi (a ser implementado em 2010) - pessoas com deficiência física (tetraplegia). 
Todas essas modalidades são planejadas pelos acadêmicos com supervisão dos professores do Departamento de Educação Física. Nossos acadêmicos vivenciam trabalhos de iniciação e de treinamento de equipes. Entendemos que estas vivências estão contribuindo para suas formações, pois notamos uma grande aderência dos mesmos, entusiasmo e satisfação em fazer parte deste processo, busca constante do conhecimento, predisposição em colaborar com os demais professores do curso e de outras disciplinas, em ajudarem nas vivências em suas aulas e o compromisso de poder estar à frente deste processo inclusivo.

Quando trabalhamos com nossos acadêmicos no projeto, buscamos conhecer a pessoa com quem estamos desenvolvendo as atividades, procurando entender sobre a natureza da sua anomalia e suas limitações, ao mesmo tempo enfatizando suas potencialidades e o que pode ser desenvolvido e melhorado. Saber estender este entendimento também para eles é um dos objetivos do projeto, pois compreendendo suas possibilidades e limitações permitirão uma maior assimilação dos resultados a serem alcançados.

É comum encontrarmos pessoas que estão com sua autoconfiança baixa em decorrência de algumas limitações ou dificuldades. Saber promover um ambiente onde possam ser desenvolvidas atividades que permitam valorizar as conquista, as vitórias sobre os desafios, a busca da autoestima, é papel importante neste processo educacional.

Todos os procedimentos metodológicos utilizados nas aulas são registrados e na medida do possível disseminados. O projeto está elaborando Cartilhas sobre como trabalhar estas modalidades paradesportivas nas associações, universidades e escolas do ensino regular. Os alunos estão se empenhando para buscar uma forma de melhor compreender seus conhecimentos tácitos.

O trabalho junto a estas modalidades esportivas tem proporcionado também a criação de metodologias e equipamentos adaptados. A maioria dos esportes oferecidos no projeto começou a ser desenvolvido com equipamentos adaptados improvisados. Esta construção possibilitou aos acadêmicos estimularem suas criatividades, permitindo uma compreensão da importância de desenvolver implementos alternativos para trabalhar com essas pessoas e, principalmente, em ambientes onde sejam difíceis de serem adquiridos.

O projeto também é um espaço para a revelação de talentos esportivos. Vários atletas que estão treinando conosco participam de competições regionais, nacionais e internacionais. Alguns atletas já tiveram a oportunidade de representar o Brasil em competições internacionais, entre elas, a Paraolimpíada de Pequim no ano de 2008. 


\section{CONSIDERAÇÕES FINAIS}

Ao finalizar este artigo, destacamos a importância para a aquisição do conhecimento do envolvimento e comprometimento de toda a comunidade acadêmica nos serviços de ensino, pesquisa e extensão desenvolvidos pelas IES. A qualificação profissional dos acadêmicos está diretamente relacionada com a sua participação nestes serviços.

Os serviços prestados pelas IES às comunidades e às organizações possibilitam disseminar o que está sendo produzido em termos de conhecimento teórico através da aplicação prática. Esta aplicação, por sua vez, fornece um feedback às mesmas instituições para novamente repensarem sobre seus conhecimentos produzidos.

A comunidade clama por serviços de qualidade e a Universidade, como celeiro do conhecimento, deve que ter o compromisso de tentar atender a essa reivindicação aos seus clientes (comunidade).

Por fim, a extensão universitária, entendida como uma forma de prestação de serviço à comunidade, deverá ser repensada, discutida e valorizada dentro da comunidade acadêmica. Ela é, além de vitrine para a comunidade, um excelente instrumento para a aquisição de novos conhecimentos. Todos os envolvidos têm a possibilidade de socializar, externarlizar, combinar e interiorizar o que está sendo produzido em termos de novos conhecimentos.

\section{REFERÊNCIAS}

BIANCHETTI, Lucídio. Aspectos históricos da apreensão e da educação dos considerados deficientes. In: __ . Um olhar sobre a diferença. Campinas/SP: Papirus, 1998. cap. 1, p. 21-51.

BRASIL. Ministério da Educação e Cultura. Secretaria de Educação Especial. Convenção de Guatemala. Convenção da Organização dos Estados Americanos. Brasília, 2001. Disponível em: <http://portal.mec.gov.br/seesp/arquivos/pdf/guatemala.pdf> . Acesso em: 13 jan. 2007.

. Ministério da Educação e Cultura. Secretaria de Educação Especial. Declaração de

Salamanca: sobre princípios, políticas e práticas na área das necessidades educativas especiais. Brasília, 1994. Disponível em:

$<$ http://portal.mec.gov.br/seesp/arquivos/pdf/salamanca.pdf $>$. Acesso em: 13 jan. 2007.

. Ministério da Educação. Parecer n⿳ 215/87 do Conselho Federal de Educação de 11 de março de 1987. Fixa os mínimos de conteúdo e duração a serem observados nos cursos de graduação em Educação Física (Bacharelado e/ou Licenciatura Plena). 
FITZSIMMONS, James A.; FITZSIMMONS, Mona J.; HORBE, Francisco J. S. Administração de serviços: operações, estratégia e tecnologia de informação. Porto Alegre: Bookman, 2000.

FONSECA, Victor. Educação especial: programa de estimulação precoce uma introdução às idéias de Feusrstein. 2. ed. Porto Alegre: Artes Médicas, 1995.

FÓRUM NACIONAL DE PRÓ-REITORES DE EXTENSÃO DAS UNIVERSIDADES PÚBLICAS BRASILEIRAS, 4., 1990, Florianópolis. Anais ...Florianópolis: Ed. UFSC,1990.

GIANESI, Irineu G. N.; CORREA, Henrique Luiz. Administração estratégica de serviços : operaçoes para a satisfação do cliente. São Paulo: Atlas, 1994.

GOFFMAN, E. Estigma: notas sobre a manipulação de identidade deteriorada. 4. ed. São Paulo: Zahar, 1982.

GRÖNROOS, C. Um modelo de qualidade de serviço e suas implicações para o marketing. RAE Revista de Administração de Empresas. São Paulo: Fundação Getúlio Vargas, v. 46, n. 4, out-dez, 2006.

HOFFMAN, K. Douglas. Marketing de Serviços. In: CZINOKATA, M. et. al. Marketing: as melhores práticas. Porto Alegre: Bookman, 2001.

KOTLER, P. Administração de Marketing: a edição do novo milênio. São Paulo: Prentice Hall, 2000.

LÃS CASAS, Alexandre L. Marketing de serviços. São Paulo: Atlas, 2006.

NOGUEIRA, Maria D. P. Extensão Universitária: diretrizes conceituais e políticas. Belo Horizonte: PROEX/UFMG; o Fórum, 2000.

2005 .

. Políticas de extensão universitária brasileira. Belo Horizonte: Editora UFMG,

NONAKA, I.; TAKEUCHI, H. Criação de conhecimento na empresa: como as empresas japonesas geram a dinâmica da inovação. Rio de Janeiro: Campus, 1997.

PARASURAMAN, A. ZEITHAML, Valarie A. BERRY, Leonardo L. Um modelo conceitual de qualidade de serviço e suas implicações para a pesquisa no futuro. RAE Revista de Administração de Empresas. São Paulo: Fundação Getúlio Vargas, v. 46, n. 4, out-dez, 2006.

RIBAS, J.B.C. O que são pessoas deficientes. São Paulo: Brasiliense, 1985.

SASSAKI, Romeu K. Como chamar as pessoas que tem deficiência? Publicado no livreto Vida Independente: história, movimento, liderança, conceito, filosofia e fundamentos. São Paulo: RNR, 2003, p. 12-16. Disponível em: 
$<$ http://www.cnbb.org.br/documento_geral/RomeuSassakiComochamaraspessoas.doc $>$. Acesso em: 15 jan 2007.

SOUZA, Ana Luiza Lima. A história da extensão universitária. Campinas,SP: Editora Alínea, 2000.

UNIVERSIDADE FEDERAL DE SANTA CATARINA. Gabinete do Reitor-Resoluções Resolução $\mathbf{N}^{\mathbf{0}} 03$ CUn/09. Dispõe sobre as normas que regulamentam as nações de extensão na Universidade Federal de Santa Catarina.. Florianópolis,2009. Disponível em: $<$ http://www.ufsc.br>. Acesso em: 10 jan. 2010.

ONU. Convention on the rights of Pernons with desabilities. Disponível em: $<$ http://www.un.org/disabilities/convention/>. NY/USA.UN. 2006. Acesso em: $11 \mathrm{de}$ fev. 2007. 